\title{
Clinical significance of Skp2 expression, alone and combined with Jab1 and p27 in epithelial ovarian tumors
}

\author{
LI SUI, YOUYI DONG, YASUO WATANABE, FUMINORI YAMAGUCHI, \\ KATSUYOSHI SUGIMOTO and MASAAKI TOKUDA
}

\author{
Department of Cell Physiology, Faculty of Medicine, Kagawa University, Kagawa, Japan
}

Received August 8, 2005; Accepted October 13, 2005

\begin{abstract}
We have previously demonstrated the inverse correlation of Jab1 and p27 proteins, as well as prognostic significance in epithelial ovarian carcinomas. In order to investigate Skp2 protein and its correlation with Jab1, p27, and clinical outcome, we evaluated Skp2 expression in a group of epithelial ovarian tumors. Immunohistochemical analysis was performed on 80 cases of ovarian tumors (33 benign and 47 malignant), and 26 of the 80 cases were evaluated by Western blot analysis. Immunofluorescence was carried out in the human ovarian adenocarcinoma cell line OVCAR-3. Skp2 expression was detected in $53.2 \%$ of malignant tumors and $18.2 \%$ of benign tumors. The positive ratio of $\mathrm{Skp} 2$ expression was increased from benign to malignant ovarian tumors $(\mathrm{p}=0.002)$. A negative correlation between Skp2 and p27 was found in benign and malignant ovarian tumors ( $\mathrm{p}=0.006$ and $\mathrm{p}<0.0001$, respectively). Skp2 expression was significantly associated with high tumor grade $(\mathrm{p}=0.001)$, lymph node metastasis $(\mathrm{p}=0.01)$, and residual disease $(\mathrm{p}=0.012)$. Kaplan-Meier survival analysis showed that Skp2 expression was significantly associated with poor prognosis $(\mathrm{p}=0.013)$, and patients with $\operatorname{Skp} 2(+) /$ Jab1(+)p27(-) expression had the worst prognosis among all phenotypes of Skp2/Jab1/p27 expression ( $\mathrm{p}=0.0007)$. Our results suggest that $\mathrm{Skp} 2$ expression was significantly associated with malignancy, and the Skp2 protein level may be a valuable prognostic factor for epithelial ovarian carcinomas. Furthermore, the combined evaluation of Skp2/Jab1/p27 proteins provides important prognostic information on patients with epithelial ovarian carcinoma.
\end{abstract}

\section{Introduction}

Skp2, S-phase kinase-associated protein 2, is a member of the specific substrate-recognition subunit of the SCF (Skp1/Cu11in/F-box) complexes from the F-box family (1).

Correspondence to: Dr Masaaki Tokuda, Department of Cell Physiology, Faculty of Medicine, Kagawa University, 1750-1 Ikenobe, Miki-Cho, Kita-Gun, Kagawa 761-0793, Japan

E-mail: tokuda@med.kagawa-u.ac.jp

Key words: Skp2, Jab1, p27, ovarian tumor
SCF complexes comprise a large family of ubiquitin ligases that contain the constant subunits, Skp1, Cullin-1 and ROC1, and a variable subunit called F-box protein (2). Each F-box protein binds a specific subset of protein substrates, and thus promotes their ligation to ubiquitin and subsequent degradation (2-4). Skp2 was originally identified as a protein that interacts with the cyclin A-cdk2 complex (1), which is necessary for DNA replication. It has been reported that Skp2 is required for the ubiquitination and subsequent proteasomal degradation of p27 protein (5-7). In cultured cells, Skp2 protein levels are cell-cycle regulated, and show an inverse pattern to that of the p27 protein $(8,9)$. Skp2 has also been implicated in the ubiquitination of other cell-cycle regulatory proteins, including cyclin $\mathrm{E}$ and the transcription factor E2F-1 (10,11). Thus, deregulation of Skp2 may contribute to neoplastic transformation through accelerated p27 proteolysis. Studies have indicated a possible relationship between Skp2 and its oncogenic potential. Our group has previously reported that the overexpression of Skp2 was significantly correlated with poor prognosis in laryngeal squamous cell carcinomas (12). Furthermore, the relationship between a high Skp2 expression level and unfavorable clinical outcome was also demonstrated in other malignant tumors (13-21).

The p27 level was inversely related to the Skp2 level in various human cancers (16-22). p27, a negative regulator of the cell cycle, is a new class of tumor suppressor (23). Reduced expression of p27 is frequently detected in human cancers (24-30), as in our previous studies $(31,32)$, and is shown to correlate with carcinogenesis and poor survival. Because p27 inhibits cyclin-CDKs in a dose-dependent manner to control cell cycle progression $(33,34)$, it is conceivable that decreased expression of p27 may result in abnormal cell proliferation in these tumors. p27 is regulated posttranscriptionally through the ubiquitin-mediated proteasome degradation pathway (35). Therefore, it is important to investigate the expression and prognostic implication of the proteins associated with the p27 degradation pathway. Jab1 (Jun activation domain-binding protein 1), another regulator of the p27 ubiquitin degradation pathway, was originally described as a transcriptional coactivator of AP1 proteins (especially c-Jun and Jun D), its coexpression with p27 accelerated the degradation of p27 by translocating p 27 from the nucleus to the cytosol where degradation could occur (36). We have previously demonstrated the expression 
Table I. Expression of Skp2, Jab1 and p27 in benign and malignant ovarian tumors.

\begin{tabular}{|c|c|c|c|c|c|c|c|c|c|c|}
\hline & \multirow[b]{2}{*}{ Total } & \multicolumn{3}{|c|}{ Skp2 } & \multicolumn{3}{|c|}{$\mathrm{J} a b 1^{\mathrm{a}}$} & \multicolumn{3}{|c|}{$\mathrm{p} 27^{\mathrm{a}}$} \\
\hline & & + & - & $\%$ & + & - & $\%$ & + & - & $\%$ \\
\hline Benign & 33 & 6 & 27 & 18.2 & 11 & 32 & 33.3 & 25 & 8 & 75.8 \\
\hline Malignant & 47 & 25 & 22 & 53.2 & 32 & 15 & 68.1 & 17 & 30 & 36.2 \\
\hline
\end{tabular}

${ }^{\mathrm{a} J a b} 1$ and p27 data are from ref. 37.

of Jab1 and its correlation with p27 in epithelial ovarian carcinoma (37), and indicated the inverse correlation of Jab1 and p27, as well as prognostic significance in human tumor.

Although we have demonstrated the importance of Jab1 in ovarian tumors, Skp2 and Jab1, two key regulators involved in the post-translational p27 degradation pathway, have not been assessed synchronously in ovarian tumors to the best of our knowledge. The aim of the present study is to investigate the expression and clinical relevance of Skp2, alone and combined with Jab1 and p27 expression in the same group of epithelial ovarian tumors.

\section{Materials and methods}

Cell culture. The human ovarian adenocarcinoma cell line OVCAR-3 (ATCC, Manassas, VA, USA) was maintained at $37^{\circ} \mathrm{C}$ in a humidified atmosphere of $5 \% \mathrm{CO}_{2}$ in RPMI-1640 medium (Sigma-Aldrich, St. Louis, MO, USA), supplemented with $10 \%$ heat-inactivated fetal calf serum, $10 \mu \mathrm{g} / \mathrm{ml}$ insulin, and antibiotics $(100 \mathrm{IU} / \mathrm{ml}$ penicillin and $100 \mu \mathrm{g} / \mathrm{ml}$ streptomycin) as recommended by the supplier.

Immunofluorescence histochemistry in OVCAR-3 cell line. In brief, the OVCAR-3 cells were spread on a CC2-treated 8-well glass slide (Lab-Tek II Chamber Slide System; Nalge Nunc International, USA), rinsed with PBS, fixed with $4 \%$ formaldehyde in PBS for 30 min, washed twice in PBS, then permeabilized with $0.5 \%$ Triton X-100 in PBS for 5 min. After washing in PBS, the cells were incubated with 5\% normal goat serum (Cappel/ICN Biomedicals, Irvine, CA) for $20 \mathrm{~min}$ at room temperature. Anti-Skp2 polyclonal antibody (1:100 in PBS; Santa Cruz Biotechnology, Santa Cruz, CA, USA), anti-p27 monoclonal antibody (1:100 in PBS; NeoMarkers, Fremont, CA, USA) were used as primary antibodies. The samples were incubated with primary antibodies for $1 \mathrm{~h}$ at room temperature. For each case, a corresponding section was incubated with PBS as a negative control. After 3 washes in PBS, the sections were incubated with a mixture of Alexa Fluor 594-conjugated anti-rabbit goat immunoglobulin G (1:500; Molecular Probes, Inc., Eugene, OR, USA) and FITC-conjugated anti-mouse goat IgG1 (1:500; Santa Cruz Biotechnology) in 1\% bovine serum albumin-PBS for $1 \mathrm{~h}$ at room temperature. The 4,6-diamino2-phenylindole (DAPI; Molecular Probes) was used as a nuclear marker, then examined with a fluorescence microscope (Nikon, Tokyo, Japan). Microscopic data were analyzed by the Meta Imaging Series 4.6 System (Universal Imaging Co., West Chester, PA, USA).
Tumor specimens. Formalin-fixed, paraffin-embedded blocks of ovarian tumor tissues from 54 patients (32 malignant and 22 benign ovarian tumors) were obtained from the Department of Perinatology and Gynecology of Faculty of Medicine, Kagawa University during 1985-1996. A total of 26 fresh ovarian tumor samples (15 malignant and 11 benign ovarian tumors) were obtained from the Department of Perinatology and Gynecology of Faculty of Medicine, Kagawa University and Department of Obstetrics and Gynecology of Takamatsu Red Cross Hospital during 1997-1998. After surgical resection, each fresh tumor specimen was immediately washed and cut out around necrotic tissue, then divided into two portions: one portion was instantly frozen for protein extraction; the other portion was formalin-fixed and paraffinembedded for routine and immunohistochemical investigation. Specimens consisted of 33 benign cystadenomas and 47 ovarian adenocarcinomas. The median age of the 47 ovarian carcinoma patients was 49 years (range, 16-77years). There were 16 patients in stage I, 3 in stage II, 16 in stage III, and 12 in stage IV, according to the International Federation of Gynecology and Obstetrics (FIGO) classification. Histological classification of tumors was carried out according to the WHO system, with 21 well-differentiated (G1), 13 moderately differentiated (G2) and 13 poorly differentiated (G3, including 2 undifferentiated) cases. Among the 47 patients with ovarian carcinomas, none received preoperative chemotherapy or radiotherapy. All received postoperative, platinum-based chemotherapy, but no radiotherapy. Follow-up data were available for all patients.

Immunohistochemistry. Paraffin sections (4 $\mu \mathrm{m}$ thickness) were deparaffinized and rehydrated. Endogenous peroxidase activity was blocked using $0.3 \%$ hydrogen peroxide $(30 \mathrm{~min})$. To reduce non-specific binding, the sections were incubated with $10 \%$ goat serum for $60 \mathrm{~min}$ at room temperature. The antigen retrieval procedure was performed by microwave oven heating ( 3 times, for $5 \mathrm{~min}$ in $10 \mathrm{mM}$ citric acid at $\mathrm{pH}$ 6.0). The sections were incubated overnight at $4^{\circ} \mathrm{C}$ with rabbit anti-Skp2 polyclonal antibody (1:50; Santa Cruz Biotechnology). For each case, a corresponding section was incubated with non-immunized rabbit serum as a negative control. Immunostaining was performed by the ABC method (avidin-biotin peroxidase complex) using a Vectastain $\mathrm{ABC}$ kit (Vector Laboratories, Burlingame, CA, USA). The peroxidase activity was detected using DAB (3,3-diaminobenzidine) as the chromogen and Mayer's hematoxylin as the counterstain. All of the samples (formalin-fixed and fresh) were handled using the same method, and the antibodies were used for both. 

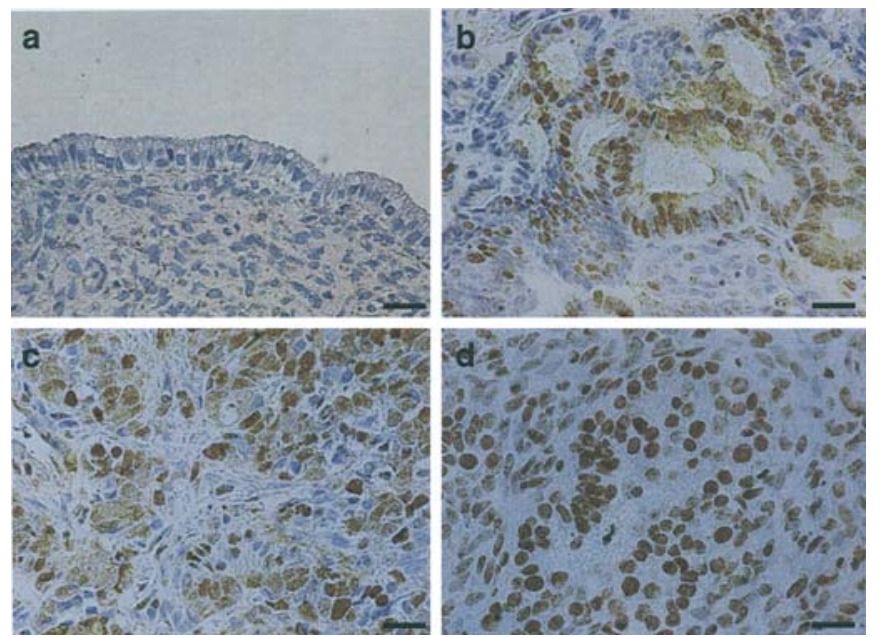

Figure 1. Immunohistochemical staining of $\mathrm{Skp} 2$ in ovarian tumors. (a) Negative nuclear staining was shown in benign ovarian tumor cells (b) Positive nuclear staining was shown in a lot of well-differentiated ovarian carcinoma cells. (c) Positive nuclear staining was shown in a large part of moderately differentiated ovarian carcinoma cells. (d) Positive nuclear staining was shown in all poorly differentiated ovarian carcinoma cells. Scale bars, $30 \mu \mathrm{m}$.

The immunoreactive cells were independently evaluated by two of our members (L.S. and Y.D.), who were unaware of the clinicopathological factors and the clinical outcome of patients. At least 20 high-power fields were chosen randomly, and 2,000 cells were counted for each case. Only cells with brown-colored nuclear staining were considered positive. A large part of benign ovarian tumors showed nuclear staining in $<10 \%$ of the tumor cells. Hence, we defined positive expression of Skp2 when $>10 \%$ of the tumor cells were stained in each section.

Western blot analysis. Approximately $0.5 \mathrm{~g}$ of tissue from each fresh tumor sample was homogenized and lysed in $2.5 \mathrm{ml}$ of lysis buffer [1\% NP-40, $150 \mathrm{mM} \mathrm{NaCl}, 50 \mathrm{mM}$ $\mathrm{NaF}, 20 \mathrm{mM}$ Tris-HCl (pH 7.5), 5 mM EDTA, $1 \mathrm{mM} \mathrm{Na}_{3} \mathrm{VO}_{4}$, $10 \mu \mathrm{M} \mathrm{Na}_{2} \mathrm{MnO}_{4}, 1 \mathrm{mM}$ PMSF, $10 \mu \mathrm{g} / \mathrm{ml}$ leupeptin, and $1 \%$ aprotinin]. The lysates were centrifuged at 100,000 rpm for $1 \mathrm{~h}$ at $4^{\circ} \mathrm{C}$, and the supernatant was stored at $-80^{\circ} \mathrm{C}$ until further analysis. The extract equivalent to $200 \mu \mathrm{g}$ of the total protein was separated by $12 \%$ SDS-polyacrylamide gel, then transferred to polyvinylidene fluoride membranes (Immobilon-P; Millipore, Bedford, MA, USA). The membranes were blocked in TBS containing 5\% nonfat dried milk, 10\% donkey serum and $0.1 \%$ Tween-20, then probed by polyclonal antibody against $\operatorname{Skp} 2$ (1:200) and B-actin (1:500; Sigma) in PBS containing $5 \%$ bovine serum. After several washes with TBS, membranes were probed with a horseradish peroxidase-conjugated anti-rabbit or anti-mouse $\operatorname{IgG}$ (Dako, Kyoto, Japan), and proteins were detected by an enhanced chemiluminescence (ECL) system (Amersham, Tokyo, Japan).

Statistical analysis. The correlation between Skp2 and clinicopathological parameters was assessed using Pearson's $\chi^{2}$ test. Spearman's rank correlation was used to determine whether there was a correlation between Skp2 and p27 or Skp2 and Jab1 expression (p27 and Jab1 data are from ref. 37). The overall survival effect of Skp2 expression, alone and
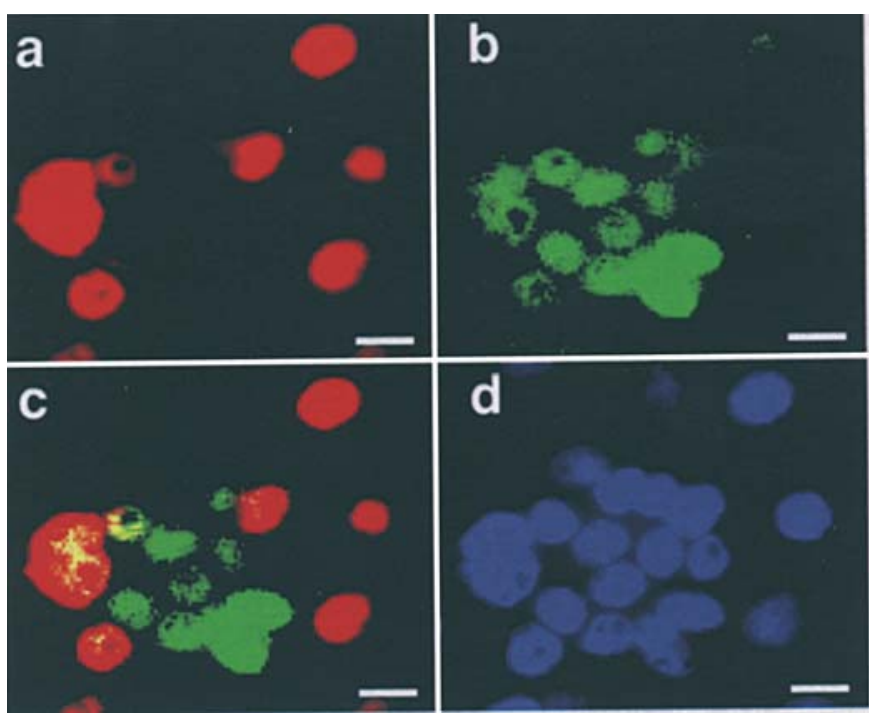

Figure 2. Double immunofluorescence staining of Skp2 and p27 in OVCAR-3 cells. (a) Nuclear staining of Skp2. (b) Nuclear staining of p27. (c) Colocalization of Skp2 with p27 by merging (yellow). (d) All nuclei were stained with DAPI. Scale bars, $10 \mu \mathrm{m}$.

in combination with p27 and Jab1, was calculated using the Kaplan-Meier method, and comparison between groups was performed with the log-rank test. The Cox proportional hazards regression model was used to estimate the relative risk ratio (RR) of death in the $95 \%$ confidence interval (CI) and identify the variables associated with overall survival. Statistical significance was set at $\mathrm{p}<0.05$. Statistical analyses were run using the JMP software version 3.2.5 (SAS Institute Inc., Cary, NC).

\section{Results}

Expression of Skp2 and its correlation with Jab1 and p27. Immunohistochemical analysis revealed that Skp2 expression was observed in the nuclei of tumor cells, and the positive ratio of Skp2 expression was enhanced from benign to malignant tumors. Examples of negative expression in benign tumors and positive expression in malignant tumors are shown in Fig. 1a-d. The expression level of Skp2 was gradually increased, accompanying poor cell differentiation in ovarian carcinoma (Fig. 1b-d). The positive ratio of Skp2 expression was $18.2 \%$ in benign and $53.2 \%$ in malignant ovarian tumors, showing a statistical significance (Table I, $\mathrm{p}=0.002$ ). The expression of Jab1 and $\mathrm{p} 27$ in our previous study was found in $33.3 \%$ and $75.8 \%$ of benign tumors, and $68.1 \%$ and $36.2 \%$ of ovarian carcinomas, respectively (Table I). The correlation between Skp2 and p27 or Skp2 and Jab1 expression was investigated by Spearman's rank correlation. A negative correlation between Skp2 and p27 was identified both in benign (correlation coefficient, -0.47 ; $\mathrm{p}=0.006$ ) and malignant tumors (correlation coefficient, $-0.71 ; \mathrm{p}<0.0001$ ). In addition, positive correlation between Skp2 and Jab1 was not demonstrated in benign (correlation coefficient, 0.33 ; $\mathrm{p}=0.058$ ) or malignant tumors (correlation coefficient, 0.27 ; $\mathrm{p}=0.064)$.

Double immunofluorescence staining has been performed in OVCAR-3 cells using anti-Skp2 and anti-p27 antibodies. The result showed that Skp2 protein is localized in the nuclei 


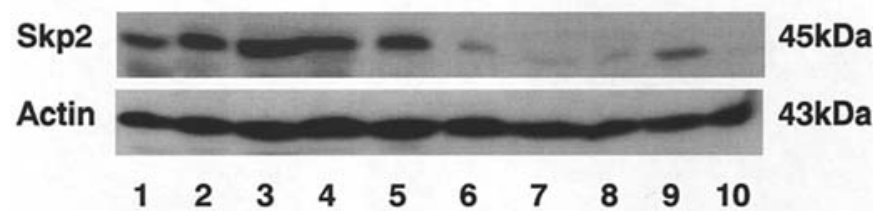

Figure 3. Western blot analysis of Skp2 in benign and malignant ovarian tumors. Malignant tumors (lanes 1-5) show high levels of expression of Skp2, and benign tumors (lanes 6-10) show low levels or no expression of Skp2. The amount of $B$-actin as a control was demonstrated at a constant level among the samples.

Table II. Correlation between Skp2 expression and clinicopathological parameters.

\begin{tabular}{|c|c|c|c|}
\hline Parameters & Total & $\begin{array}{c}\text { Skp2 } \\
\text { expression }(\%)\end{array}$ & $\mathrm{p}$-value \\
\hline \multicolumn{4}{|l|}{ Age } \\
\hline$\leq 60$ & 37 & $20(54.1)$ & \\
\hline$>60$ & 10 & $5(50.0)$ & 0.819 \\
\hline \multicolumn{4}{|l|}{ Stage } \\
\hline I-II & 19 & $8(42.1)$ & \\
\hline III-IV & 28 & $17(60.7)$ & 0.209 \\
\hline \multicolumn{4}{|l|}{ Grade } \\
\hline G1 & 21 & $5(23.8)$ & \\
\hline G2 & 13 & $9(69.2)$ & \\
\hline G3 & 13 & $11(84.6)$ & 0.001 \\
\hline \multicolumn{4}{|l|}{ Histology } \\
\hline Serous & 20 & $9(45.0)$ & \\
\hline Mucinous & 14 & $6(42.9)$ & \\
\hline Endometrioid & 6 & $5(83.3)$ & \\
\hline Clear cell & 5 & $3(60.0)$ & \\
\hline Undifferentiated & 2 & $2(100.0)$ & 0.269 \\
\hline \multicolumn{4}{|l|}{ Lymph node } \\
\hline Negative & 19 & $6(31.6)$ & \\
\hline Positive & 24 & $17(70.8)$ & 0.010 \\
\hline \multicolumn{4}{|l|}{ Ascites } \\
\hline Negative & 15 & $5(33.3)$ & \\
\hline Positive & 32 & $20(62.5)$ & 0.062 \\
\hline \multicolumn{4}{|l|}{ Residual disease } \\
\hline$\leq 2 \mathrm{~cm}$ & 25 & $9(36.0)$ & \\
\hline$>2 \mathrm{~cm}$ & 22 & $16(72.7)$ & 0.012 \\
\hline
\end{tabular}

of OVCAR-3 cells. The cells with Skp2 expression are usually negative for $\mathrm{p} 27$ expression, while those with p27 expression are usually negative for Skp2 expression (Fig. 2a-d).

To confirm the specificity of the immunohistochemical results, Western blot analysis was carried out in 11 benign and 15 malignant ovarian tumors, in which freshly frozen materials were available. An example of Western blot analysis is shown in Fig. 3. Immunoreactive bands of Skp2 at
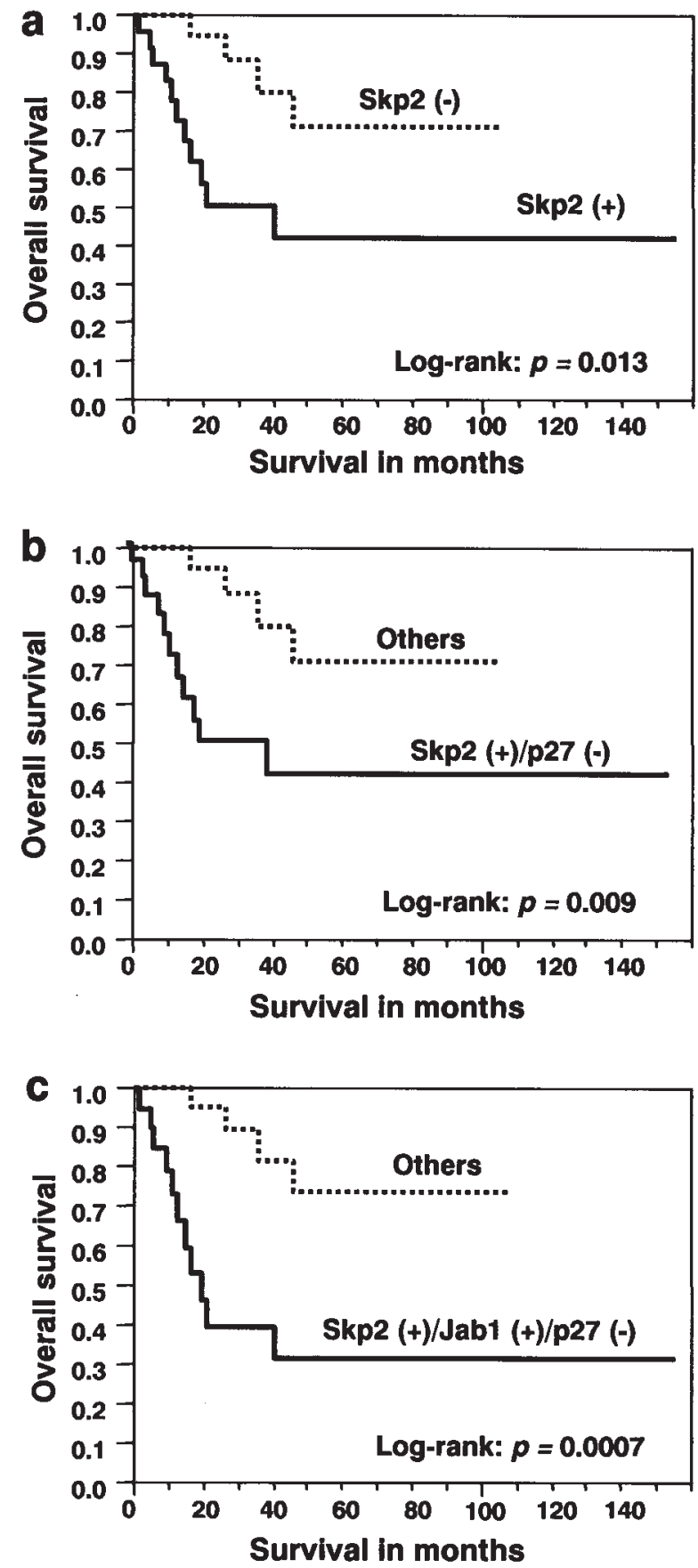

Figure 4. Kaplan-Meier survival curves of patients with ovarian carcinoma (a) Overall survival according to $\mathrm{Skp} 2$ expression $(\mathrm{p}=0.013)$. (b) Overall survival according to $\mathrm{Skp} 2 / \mathrm{p} 27$ phenotypes $(\mathrm{p}=0.009)$. (c) Overall survival according to Skp2/Jab1/p27 phenotypes ( $\mathrm{p}=0.0007)$.

$45 \mathrm{kDa}$ were seen in all 5 cases of ovarian carcinomas (lanes 1-5), while low or no Skp2 expression was observed in 5 cases of benign tumors (lanes 6-10).

Correlation between Skp2 expression and clinicopathological parameters. In addition, the correlation between Skp2 expression and clinicopathological parameters such as tumor grades, clinical stages, histology and lymph node status is summarized in Table II. Increased Skp2 expression was significantly associated with high tumor grade $(\mathrm{p}=0.001)$, lymph node metastasis $(\mathrm{p}=0.01)$, and residual disease $(\mathrm{p}=0.012)$. 
Survival analysis. The median follow-up time for all patients was 24 months (range, 2-156 months). At the end of the follow-up, 32 patients survived with a median follow-up time of 27.5 months (range, 4-156 months), and 15 had died of ovarian cancer after a median follow-up time of 17 months (range, 2-46 months). The Kaplan-Meier survival analysis showed that Skp2 expression has a significant adverse effect on overall survival ( $\mathrm{p}=0.013$; Fig. $4 \mathrm{a}$ ). In our previous study, increased Jab1 expression or decreased p27 expression was significantly associated with worse overall survival ( $\mathrm{p}=0.019$ or $\mathrm{p}=0.049$; data from ref. 37 ), and patients with Jab1(+)/p27(-) expression had a significantly worse overall survival than others with single protein expression $(\mathrm{p}=0.008)$. In the present study, we also analyzed the combined phenotypes of Skp2 and p27 proteins, and patients with Skp2(+)/p27(-) expression had the worst overall survival among all phenotypes of Skp2/p27 expression ( $\mathrm{p}=0.009$; Fig. 4b). When the combined phenotypes of three proteins were analyzed, patients with the $\operatorname{Skp} 2(+) / \mathrm{Jab} 1(+) / \mathrm{p} 27(-)$ expression had the worst prognosis in all phenotypes of Skp2/Jab1/p27 expression ( $\mathrm{p}=0.0007$; Fig. 4c).

The Cox proportional hazard regression analysis showed that combined phenotypes of $\operatorname{Skp} 2(+) / \mathrm{p} 27(-)(\mathrm{p}=0.01$; RR, 2.01; CI, 1.17-3.83), Jab1(+)/p27(-) (p=0.009; RR, 2.04; CI, 1.19-3.89), and Skp2(+)/Jab1(+)/p27(-) (p=0.001; RR, 2.41; CI, 1.40-4.59) were significantly associated with the overall survival of patients, and the risk ratio of the $\operatorname{Skp} 2(+) / \mathrm{Jab} 1(+) /$ p27(-) phenotype was the highest.

\section{Discussion}

Skp2, a specific ubiquitin subunit that targets $\mathrm{p} 27$ for degradation (5-7), has shown an inverse relationship with p27 in many malignant tumors (13-22). Jab1 coexpression with p27 accelerated the degradation of p27 by translocating p27 from the nucleus to the cytosol where degradation could occur (36). These findings suggested that Skp2 and Jab1 are two pivotal regulators for p27 degradation. In our series, we have reported the expression of Jab1 and p27 as well as their clinical significance in the same samples of benign and malignant epithelial ovarian tumors (37). The result showed that Jab1 expression is inversely correlated with p27 expression levels, suggesting that Jab1 as a negative regulator of p27 was associated with the development, progression, and prognosis of epithelial ovarian tumors.

In the present study, Skp2 expression was immunohistochemically examined in ovarian tumors, and immunofluorescence was performed on the OVCAR-3 cell line. We observed that Skp2 expression was mainly located in the nuclei of tumor cells, and usually showed an inverse topographical distribution with $\mathrm{p} 27$. Skp2 overexpression occurred in $53.2 \%$ of ovarian carcinomas, and $18.2 \%$ of benign tumors. The positive ratio of Skp2 expression was increased with the malignancy of ovarian tumors, showing important statistical significance. Western blot analysis also confirmed the different Skp2 expression levels in the samples of benign and malignant ovarian tumors. Inhibition of the conversion from a benign to malignant tumor might be a useful strategy in the treatment of ovarian carcinoma. Our study suggested that increased Skp2 levels might contribute to the malignant phenotype of ovarian tumors. Also, a negative correlation between Skp2 and p27 expression was found in benign and malignant ovarian tumors. A positive correlation between Skp2 and Jab1 was not observed in benign or malignant ovarian tumors. It has been reported that the expression of Skp2 is up-regulated in various types of cancer, and the Skp2 gene is considered an oncogene $(15,16)$.

The malignant conversion of a tumor is a complex process, which is regulated in part by increased expression of Skp2 and decreased expression of $\mathrm{p} 27$. Overexpression of Skp2 may represent an important mechanism of malignant transformation of ovarian epithelial cells by enhancing p27 degradation. The inverse correlation between Jab1 and p27 has been demonstrated by our previous studies $(37,38)$ and others (39-42). To date, no study has been performed for Skp2, Jab1 and p27 expression using the same group of ovarian tumor specimens, and the present study is the first to provide a valuable comparison of these three important proteins. In Skp2 and Jab1, two negative regulators of $\mathrm{p} 27$, a positive correlation was not observed in our present study, which is consistent with the study by Fukayama et al on lung adenocarcinoma (39). This may be explained by Skp2 and Jab1 regulating p27 degradation through different pathways. A report by Kamura et al indicated that the degradation of p27 is regulated by two distinct mechanisms: translocation-coupled cytoplasmic ubiquitination by KPC (Kip1 ubiquitinationpromoting complex) at G1 phase and nuclear ubiquitination by Skp2 at S and G2 phases (43), and the nuclear export of p27 by CRM1 (a carrier protein for nuclear export) $(44,45)$ appears to be necessary for KPC-mediated proteolysis (43). Furthermore, the CRM1-induced nuclear export of p27 needs Jab1 as an adaptor (46). Taken together, we can conclude that Jab1 may degrade p 27 by CRM1 and KPC at G1 phase, while Skp2 may degrade p27 at S and G2 phases.

In addition, we evaluated the correlation between Skp2 and clinicopathological parameters, as well as the prognosis of patients. We found that Skp2 expression was significantly associated with high tumor grade, lymph node metastasis, and residual disease. It has been reported that Skp2 expression significantly correlates with the grade of malignancy in lymphomas $(14,22)$, prostate cancer $(20)$, and lymph node metastasis in laryngeal (12) and oral squamous cell carcinomas (40). Shigemasa et al reported that Skp2 expression correlated with advanced clinical stage and serous adenocarcinoma in ovarian tumors (47). The discrepancy with our data may be explained by different interpretation criteria (stage I vs. stage II/III/ IV; grade 1 vs. grade 2/3; cut-off value of 5\%), as well as patient selection.

Results of the survival analysis showed that Skp2 expression was significantly associated with poor prognosis. We have performed the survival analysis of p27 and Jab1 expression in epithelia ovarian tumors (37), and found that patients with Jab1(+)p27(-) expression had a significantly decreased overall survival than other phenotypes of Jab1/p27 expression $(\mathrm{p}=0.008)$. When $\mathrm{Skp} 2$ was analyzed using combined phenotypes with $\mathrm{p} 27$, we found that patients with Skp2(+)/p27(-) expression had the worst overall survival among all phenotypes of Skp2/p27 expression. In order to verify whether combined analysis of these proteins can provide a more important significance in the prognostic 
evaluation of ovarian carcinoma patients, the combined phenotype of Skp2, Jab1, and p27 expression were examined. More interestingly, these three proteins together revealed the greatest prognostic potential compared to other phenotypes. Patients with Skp2(+)/Jab1(+)/p27(-) expression had the worst overall survival among all phenotypes of Skp2/Jab1/p27 expression. Our findings suggest that the combined evaluation of Skp2/Jab1/p27 proteins might obtain the most reliable indication of prognosis. Also, such information could provide better planning of appropriate treatment strategies for individual patient subgroups.

In conclusion, Skp2 expression was increased in malignant ovarian tumors, and inversely correlated with p27 expression. Skp2 and Jab1, as two negative regulators of p27 degradation pathways, may play an important role in the malignancy transformation of ovarian tumors by enhancing p27 degradation. Furthermore, the combined evaluation of Skp2/Jab1/p27 proteins provides important prognostic information on epithelial ovarian carcinomas.

\section{Acknowledgements}

We thank Drs. Masayuki Ohno (Department of Perinatology and Gynecology, Faculty of Medicine, Kagawa University, Kagawa, Japan), Teruo Inohara and Masaki Goto (Department of Obstetrics and Gynecology of Takamatsu Red Cross Hospital, Kagawa, Japan) for providing the tumor specimens. This work was supported by a Grant-in Aid for Scientific Research from the Ministry of Education, Culture, Sports, Science and Technology of Japan.

\section{References}

1. Zhang H, Kobayashi R, Galaktionov K and Beach D: p19Skp1 and p45Skp2 are essential elements of the cyclin A-CDK2 S phase kinase. Cell 82: 915-925, 1995.

2. Deshaies R: SCF and Cullin/Ring H2 based ubiquitin ligases. Annu Rev Cell Dev Biol 15: 435-467, 1999.

3. Patton EE, Willems AR and Tyers M: Combinatorial control in ubiquitin-dependent proteolysis: don't Skp the F-box hypothesis. Trends Genet 14: 236-243, 1998.

4. Kipreos ET and Pagano M: The F-box protein family. Genome Biol 1: 3002.1-3002.7, 2000.

5. Carrano AC, Eytan E, Hershko A and Pagano M: SKP2 is required for ubiquitin-mediated degradation of the $\mathrm{CDK}$ inhibitor p27. Nat Cell Biol 1: 193-199, 1999.

6. Sutterluty H, Chatelain E, Marti A, Wirbelauer C, Senften M, Muller U and Krek W: p45SKP2 promotes p27Kip1 degradation and induces S phase in quiescent cells. Nat Cell Biol 1: 207-214, 1999.

7. Tsvetkov LM, Yeh KH, Lee SJ, Sun H and Zhang H: p27(Kip1) ubiquitin and degradation is regulated by the SCF (Skp2) complex through phosphorylated Thr187 in p27. Curr Biol 9: 661-664, 1999.

8. Bilodeau M, Talarmin H, Ilyin G, et al: Skp2 induction and phosphorylation is associated with the late G1 phase of proliferating rat hepatocytes. FEBS Lett 452: 247-253, 1999.

9. Nakayama K, Nagahama H, Minamishima YA, et al: Targeted disruption of Skp2 results in accumulation of cyclin $\mathrm{E}$ and p27(Kip1), polyploidy and centrosome overduplication. EMBO J 19: 2069-2081, 2000.

10. Nakayama KI, Hatakeyama S and Nakayama K: Regulation of the cell cycle at the $\mathrm{G}(1)-\mathrm{S}$ transition by proteolysis of cyclin $\mathrm{E}$ and p27(Kip1). Biochem Biophys Res Commun 282: 853-860, 2001.

11. Marti A, Wirbelauer C, Scheffner M and Krek W: Interaction between ubiquitin-protein ligase SCFSKP2 and E2F-1 underlies the regulation of E2F-1 degradation. Nat Cell Biol 1: 14-19, 1999.
12. Dong Y, Sui L, Watanabe Y, Sugimoto K and Tokuda M: S-phase kinase-associated protein 2 expression in laryngeal squamous cell carcinomas and its prognostic implications. Oncol Rep 10: 321-325, 2003.

13. Kudo Y, Kitajima S, Sato S, Miyauchi M, Ogawa I and Takata T: High expression of S-phase kinase-interacting protein 2, human F-box protein, correlates with poor prognosis in oral squamous cell carcinomas. Cancer Res 61: 7044-7047, 2001.

14. Oliveira AM, Okuno SH, Nascimento AG and Lloyd RV: Skp2 protein expression in soft tissue sarcomas. J Clin Oncol 21: 722-727, 2003.

15. Latres E, Chiarle R, Schulman BA, Pavletich NP, Pellicer A, Inghirami $\mathrm{G}$ and Pagano $\mathrm{M}$ : Role of the F-box protein Skp2 in lymphomagenesis. Proc Natl Acad Sci USA 98: 2515-2520, 2001 .

16. Gstaiger M, Jordan R, Lim M, Catzavelos C, Mestan J, Slingerland J and Krek W: Skp2 is oncogenic and overexpressed in human cancers. Proc Natl Acad Sci USA 98: 5043-5048, 2001.

17. Hershko D, Bornstein G, Ben-Izhak O, Carrano A, Pagano M, Krausz MM and Hershko A: Inverse relation between levels of p27(Kip1) and of its ubiquitin ligase subunit Skp2 in colorectal carcinomas. Cancer 91: 1745-1751, 2001.

18. Masuda $\mathrm{T}$, Inoue $\mathrm{H}$, Sonoda $\mathrm{H}$, et al: Clinical and biological significance of S-phase kinase-associated protein (Skp2) gene expression in gastric carcinoma: modulation of malignant phenotype by Skp2 overexpression, possibly via p27 proteolysis. Cancer Res 62: 3819-3825, 2002.

19. Yang G, Ayala G, De Marzo A, et al: Elevated Skp2 protein expression in human prostate cancer: association with loss of the cyclindependent kinase inhibitor p27 and PTEN and with reduced recurrencefree survival. Clin Cancer Res 8: 3419-3426, 2002.

20. Ben-Izhak O, Lahav-Baratz S, Meretyk S, et al: Inverse relationship between Skp2 ubiquitin ligase and the cyclin dependent kinase inhibitor p27Kip1 in prostate cancer. J Urol 170: 241-245, 2003.

21. Lim MS, Adamson A, Lin Z, et al: Expression of Skp2, a p27(Kip1) ubiquitin ligase, in malignant lymphoma: correlation with p27(Kip1) and proliferation index. Blood 100: 2950-2956, 2002.

22. Chiarle R, Budel LM, Skolink J, et al: Increased proteasome degradation of cyclin-dependent kinase inhibitor p27 is associated with a decreased overall survival in mantle cell lymphoma. Blood 95: 619-626, 2000

23. Fero ML, Randel E, Gurley KE, Roberts JM and Kemp CJ: The murine gene p27Kip1 is haplo-insufficient for tumour suppression. Nature 396: 177-180, 1998

24. Catzavelos C, Bhattacharya N, Ung YC, et al: Decreased levels of the cell-cycle inhibitor p27Kip1 protein: prognostic implications in primary breast cancer. Nat Med 3: 227-230, 1997.

25. Porter PL, Malone KE, Heagerty PJ, et al: Expression of cellcycle regulators $\mathrm{p} 27 \mathrm{Kip} 1$ and cyclin $\mathrm{E}$, alone and in combination, correlate with survival in young breast cancer patients. Nat Med 3: 222-225, 1997.

26. Cordon-Cardo C, Koff A, Drobnjak M, et al: Distinct altered patterns of $\mathrm{p} 27 \mathrm{KIP} 1$ gene expression in benign prostatic hyperplasia and prostatic carcinoma. J Natl Cancer Inst 90: 1284-1291, 1998.

27. Mori M, Mimori K, Shiraishi T, Tanaka S, Ueo H, Sugimachi K and Akiyoshi T: p27 expression and gastric carcinoma. Nat Med 3: 593,1997

28. Esposito V, Baldi A, De Luca A, et al: Prognostic role of the cyclin-dependent kinase inhibitor p27 in non-small cell lung cancer. Cancer Res 57: 3381-3385, 1997.

29. Florenes VA, Maelandsmo GM, Kerbel RS, Slingerland JM, Nesland JM and Holm R: Protein expression of the cell-cycle inhibitor p27Kip1 in malignant melanoma: inverse correlation with disease-free survival. Am J Pathol 153: 305-312, 1998.

30. Loda M, Cukor B, Tam SW, et al: Increased proteasomedependent degradation of the cyclin-dependent kinase inhibitor p27 in aggressive colorectal carcinomas. Nat Med 3: 231-234, 1997.

31. Sui L, Dong Y, Ohno M, et al: Implication of malignancy and prognosis of p27(kip1), Cyclin E, and Cdk2 expression in epithelial ovarian tumors. Gynecol Oncol 83: 56-63, 2001.

32. Tamura N, Dong Y, Sui L, Tai Y, Sugimoto K, Nagahata S and Tokuda M: Cyclin-dependent kinase inhibitor p27 is related to cell proliferation and prognosis in laryngeal squamous cell carcinomas. J Laryngol Otol 115: 400-406, 2001. 
33. Lee MH, Reynisdottir I and Massague J: Cloning of p57KIP2, a cyclin-dependent kinase inhibitor with unique domain structure and tissue distribution. Genes Dev 9: 639-649, 1995.

34. Polyak K, Lee MH, Erdjument-Bromage H, Koff A, Roberts JM, Tempst P and Massague J: Cloning of p27Kip1, a cyclindependent kinase inhibitor and a potential mediator of extracellular antimitogenic signals. Cell 78: 59-66, 1994.

35. Pagano M, Tam SW, Theodoras AM, et al: Role of the ubiquitinproteasome pathway in regulating abundance of the cyclindependent kinase inhibitor p27. Science 269: 682-685, 1995.

36. Tomoda K, Kubota Y and Kato J: Degradation of the cyclindependent-kinase inhibitor p27Kip1 is instigated by Jab1. Nature 398: 160-165, 1999.

37. Sui L, Dong Y, Ohno M, Watanabe Y, Sugimoto K, Tai Y and Tokuda M: Jab1 expression is associated with inverse expression of p27(kip1) and poor prognosis in epithelial ovarian tumors. Clin Cancer Res 7: 4130-4135, 2001.

38. Dong Y, Sui L, Watanabe Y, Yamaguchi F, Hatano N and Tokuda M: Prognostic significance of Jab1 expression in laryngeal squamous cell carcinomas. Clin Cancer Res 11: 259-266, 2005.

39. Goto A, Niki T, Moriyama S, et al: Immunohistochemical study of Skp2 and Jab1, two key molecules in the degradation of P27, in lung adenocarcinoma. Pathol Int 54: 675-681, 2004.

40. Shintani S, Li C, Mihara M, Hino S, Nakashiro K and Hamakawa H: Skp2 and Jab1 expression are associated with inverse expression of $\mathrm{p} 27(\mathrm{KIP} 1)$ and poor prognosis in oral squamous cell carcinomas. Oncology 65: 355-362, 2003.
41. Kouvaraki MA, Rassidakis GZ, Tian L, Kumar R, Kittas C and Claret FX: Jun activation domain-binding protein 1 expression in breast cancer inversely correlates with the cell cycle inhibitor p27(Kip1). Cancer Res 63: 2977-2981, 2003.

42. Rassidakis GZ, Claret FX, Lai R, Zhang Q, Sarris AH, McDonnell TJ and Medeiros LJ: Expression of p27(Kip1) and c-Jun activation binding protein 1 are inversely correlated in systemic anaplastic large cell lymphoma. Clin Cancer Res 9: 1121-1128, 2003.

43. Kamura T, Hara T, Matsumoto M, et al: Cytoplasmic ubiquitin ligase KPC regulates proteolysis of p27(Kip1) at G1 phase. Nat Cell Biol 6: 1229-1235, 2004.

44. Ishida N, Hara T, Kamura T, Yoshida M, Nakayama K and Nakayama KI: Phosphorylation of p27Kip1 on serine 10 is required for its binding to CRM1 and nuclear export. J Biol Chem 277: 14355-14358, 2002.

45. Connor MK, Kotchetkov R, Cariou S, et al: CRM1/Ran-mediated nuclear export of p27(Kip1) involves a nuclear export signal and links p27 export and proteolysis. Mol Biol Cell 14: 201-213, 2003.

46. Tomoda K, Kubota Y, Arata Y, et al: The cytoplasmic shuttling and subsequent degradation of p27Kip 1 mediated by Jab1/ CSN5 and the COP9 signalosome complex. J Biol Chem 277: 2302-2310, 2002.

47. Shigemasa K, Gu L, O'Brien TJ and Ohama K: Skp2 overexpression is a prognostic factor in patients with ovarian adenocarcinoma. Clin Cancer Res 9: 1756-1763, 2003. 